CESIS Electronic Working Paper Series

Paper No. 327

\title{
Testing for Panel Unit Roots under General Cross- Sectional Dependence
}

\author{
Thomas Holgersson \\ Kristofer Månsson \\ Ghazi Shukur
}

October, 2013 


\title{
Testing for Panel Unit Roots under General Cross-Sectional Dependence
}

\author{
H.E.T. Holgersson ${ }^{1}$, K. Månsson ${ }^{2}$ and G. Shukur ${ }^{3}$ \\ ${ }^{1,2 \& 3}$ Department of Economics, Finance and Statistics \\ Jönköping International Business School, Box 1026, 55111 Sweden \\ ${ }^{1 \& 3}$ Department of Economics and Statistics, Linnaeus University, Sweden
}

\begin{abstract}
In this paper we generalize four tests of multivariate linear hypothesis to panel data unit root testing. The test statistics are invariant to certain linear transformations of data and therefore simulated critical values may conveniently be used. It is demonstrated that all four tests remains well behaved in cases of where there are heterogeneous alternatives and crosscorrelations between marginal variables. A Monte Carlo simulation is included to compare and contrast the tests with two well-established ones.
\end{abstract}

Keywords: Panel data, unit roots, linear hypothesis, invariance.

JEL: C32, C52 


\section{Introduction}

In order to assess stationarity of a process, it is common to express it by means of a statistical model. Traditionally this has been done using a first-order autoregression model where the stationarity is assessed through tests of the linear restrictions on the autoregression parameter - see, for example, Fuller (1996), Dickey and Fuller (1979), Said and Dickey (1984) and Ng and Perron (1995). These tests, however, are designed for univariate processes, and it is by no means obvious how to extend a univariate test to a multivariate setting of, say, $N$ variables such as in a panel data context, though some tests of different origin have been considered in the literature. Breitung and Meyer (1994) suggested a panel data unit root test valid for a fixed number of observations $T$ and $N \rightarrow \infty$. Apart from the assumption of increasing $N$, their test, as well as the test proposed by Levin, Lin and Chu (2002), assumes a common scalar parameter, which does not allow some marginal series to be unit roots and others not. Im, Pesaran and Shin (2003) relaxed the assumption of a common parameter and proposed a test based on averaging the test statistics from the $N$ cross-section units. Another test which allows for heterogeneous parameters over the $N$ units was introduced by Maddala (1977), who used Fishers $p$-value statistic $-2 \sum_{i=1}^{N} \log P_{i}$ where $P_{i}$ is the $p$-value of any univariate test of the $i$ th marginal process. This, as well as the other panel data tests above, does not allow for crosssectional correlations, which in turn appear to be present in most cases met in practice. In such cases, Maddala and Wu (1999) suggest using 'bootstrap' methods to obtain fair, critical values of Fisher's test. A somewhat different test was proposed by Moon and Perron (2004), who assumed a factor structure of the cross-covariances and suggested pooling defactored variables to construct a unit root test. Other factor-based methods for cross-correlated data have been proposed by Phillips and Sul (2003), Bai and Ng (2004), Choi (2002) and Pesaran (2003).

In this paper, we will take a different approach to panel data unit root testing, which simultaneously allows for heterogeneous unit roots - in the sense that some series may be stationary and others not - and cross-correlations of the residuals without assuming a factor structure. We specify the panel unit root problem in the form of a multidimensional restriction on a linear, but (possibly) non-stationary, vector process and four invariant statistics for testing the hypothesis. As each of the proposed statistics is invariant to linear transformations, the critical values may be simulated by computers with arbitrary precision, thereby avoiding the problem of deriving the complicated null distribution, so that completely feasible 
procedures are available. The power properties of the four tests are investigated through Monte Carlo simulations, and, for the purpose of comparison, the frequently used test proposed by Im, Pesaran, Shin (2003) is included. The tests are applied to panels of 5, 10, 15 and 20 units with samples ranging from 30 to 500 observations under different null [OK?] and alternative parameter settings.

The paper is arranged as follows. In the next section we specify the model under investigation with the corresponding null and alternative hypotheses along with the proposed tests. The Monte Carlo simulations are presented in Section 3. In Section 4 we present the results as regards the size and power of the tests and finally, a conclusive summary is presented in Section 5.

\section{Panel unit root testing}

In this section we present the model and outline of the hypothesis tests. Since nearly all previously proposed successful unit root tests involved a first-order autoregressive model, with possible extensions thereof, we will follow that principle here (for a survey of approaches, see Pesaran 2007). Consider a multivariate, possibly non-stationary process defined by

$$
\mathbf{Y}_{t}=\boldsymbol{\rho} \mathbf{Y}_{t-1}+\mathbf{u}_{t}
$$

where $t=1, \ldots, T, \mathbf{u}_{t} \sim N(\mathbf{0}, \boldsymbol{\Sigma})$ and $\boldsymbol{\Sigma}: N \times N$ is a positive semi-definite (psd) matrix of residual covariances, and $\boldsymbol{\rho}: N \times N$ is a parameter matrix where $\rho_{i j}=0$ for $i \neq j$ by assumption. The null and alternative hypothesis of (multivariate) unit root may then be expressed by

$$
\begin{aligned}
& H_{0}: \rho_{11}=\ldots=\rho_{N N}=1 \\
& H_{A}: \rho_{i i}<1, \exists_{i}
\end{aligned} .
$$

In order to test this hypothesis it is convenient to take the first difference of the observable variable to get

$$
\nabla \mathbf{Y}_{t}=\mathbf{Y}_{t}-\mathbf{Y}_{t-1}=(\boldsymbol{\rho}-\mathbf{I}) \mathbf{Y}_{t-1}+\mathbf{u}_{t}
$$

On the difference form, the hypothesis may be expressed as

$$
\begin{aligned}
& H_{0}:\left(\rho_{11}-1\right)=\ldots=\left(\rho_{N N}-1\right)=0 \\
& H_{A}:\left(\rho_{i i}-1\right)<0, \exists_{i}
\end{aligned}
$$


or equivalently,

$$
\begin{aligned}
& H_{0}:(\boldsymbol{\rho}-\mathbf{I})=\mathbf{0} \\
& H_{A}:(\boldsymbol{\rho}-\mathbf{I}) \neq \mathbf{0}
\end{aligned}
$$

Note that, in view of (2.2), this is simply a hypothesis of $N$ restrictions in a linear model, which in turn is a well-established problem in multivariate analysis where test statistics are usually computed through functions of the restricted and unrestricted residual sum-of-square matrixes. A common procedure may be described as follows. Let $\mathbf{S}_{R}$ and $\mathbf{S}_{U}$ denote the restricted and unrestricted residual covariance matrixes of (2.2) and define $\mathbf{H}=T\left(\mathbf{S}_{R}-\mathbf{S}_{U}\right)$ and $\mathbf{E}=T \mathbf{S}_{U}$ where $T$ is the total number of available observations after the differentiation where, by assumption, $T>N+2$. These statistics are known as the hypothesis and error matrixes in the literature, and are the main ingredients within several well-known test statistics. Some options are presented below:

$$
\begin{aligned}
& T_{0}^{2}=T \cdot \operatorname{trace}\left(\mathbf{H E}^{-1}\right) \\
& V=T \cdot \operatorname{trace}\left(\mathbf{H}(\mathbf{H}+\mathbf{E})^{-1}\right) \\
& \Lambda=\operatorname{det}(\mathbf{E}) / \operatorname{det}(\mathbf{H}+\mathbf{E}) \\
& R \propto \Lambda^{-1 / s}, s=\left(\left(N^{4}-4\right) /\left(2 N^{2}-5\right)\right)^{1 / 2} .
\end{aligned}
$$

The $T_{0}^{2}$ statistic was initially proposed by Lawley (1938) and Hotelling (1947), and is also sometimes labeled as the 'Wald statistic'. For a one-dimensional variable this statistic is proportional to the standard Dickey-Fuller $t$ statistic. The $V$ statistic is known as the 'Pillai's trace' (Pillai, 1955, 1956) and has also been derived through a Lagrangean multiplier prespective (e.g. Judge et. al. 1985). The $\Lambda$ statistic is known as 'Wilks lambda', while the $R$ statistic was introduced by Rao (1973). Further references concerning their origin, inequality ordering and null- and alternative distributions may be found in Muirhead (2005), Rao (1973), Judge et. al. (1985), Anderson (2003), Bewley (1986), Fujikoshi (1970, 1988), Kibria and Saleh (2005) and Lee (1971). These four statistics were originally derived for the purpose of testing linear hypothesis in contexts of multivariate linear models such as MANOVA and other multivariate settings. But they have also proven to be useful for testing distributional assumptions in multivariate econometric models. For example, Edgerton and Shukur (1999) and Holgersson (2004) used them to assess autocorrelation in multivariate regression and seemingly unrestricted regression (SUR) models, while Holgersson and Shukur (2004) used 
them to test for multivariate heteroscedastricity. In these cases, the authors used tabulated or asymptotical critical values obtained within the references above. For non-stationary processes these critical values are not valid. But each of the four statistics is invariant to linear transformations of the kind $\mathbf{Y} \mapsto \mathbf{B Y}$ for any non-singular matrix $\mathbf{B}$, and the critical values may be simulated with arbitrary precision by computers. However, unit root tests in econometrics are frequently conducted on a series of logarithms, which are not invariant to such transformations (i.e. to changes from measures using one currency to another) since the logarithm would add a constant to the series. It is therefore common to add a constant to the model to also make the statistic invariant to these changes. For example, we may write $\mathbf{Y}_{t}=\mathbf{a}+\mathbf{Z}_{t}$ where $\mathbf{Z}_{t}=\boldsymbol{\rho} \mathbf{Z}_{t-1}+\mathbf{u}_{t}$. By eliminating $\mathbf{Z}_{t}$ from this model we get

$$
\mathbf{Y}_{t}=\mathbf{a}^{*}+\boldsymbol{\rho} \mathbf{Y}_{t-1}+\mathbf{u}_{t}, \quad \mathbf{a}^{*}=\left(\left(1-\rho_{11}\right) a_{1}, \ldots,\left(1-\rho_{N N}\right) a_{N}\right)^{\prime}
$$

Note that the $i$ : th element of $\mathbf{a}^{*}$ is zero when $\rho_{i i}$ is zero. In other words, the joint hypothesis of $\left(\rho_{i i}=1\right) \cap\left(a_{i}=0\right)$ rules out the possibility that $\mathbf{Y}_{t}$ is a random walk with drift. Any of the statistics (2.4) to (2.7) may be used for testing the extended hypothesis after appropriate degrees of freedom adjustments. It is also possible to construct other tests based on the eigenvalues of $\left\{\lambda_{n}\right\}$ of $\mathbf{H E}^{-1}$. Perlman and Olkin (1980) showed that any test with an acceptance region $g\left(\lambda_{1}, \ldots, \lambda_{N}\right) \leq c$ where $g$ is non-decreasing in each argument, is unbiased. These authors also supplied monotonicity results for the power functions of such tests. In this paper, however, we will restrict ourselves to those of (2.4) to (2.7) due to their simple functional form. In order to obtain these statistics the restricted and unrestricted sum-ofsquare residual matrixes need to be estimated. The most efficient way to do this is through the SUR version of model (2.2). This is defined as follows:

$$
\left[\begin{array}{c}
\nabla \mathbf{Y}_{1, t} \\
\vdots \\
\nabla \mathbf{Y}_{N, t}
\end{array}\right]_{N T \times 1}=\left[\begin{array}{ccc}
\left(\mathbf{1}, \mathbf{Y}_{1, t-1}\right) & & (\mathbf{0}) \\
& \ddots & \\
(\mathbf{0}) & & \left(\mathbf{1}, \mathbf{Y}_{N, t-1}\right)
\end{array}\right]\left[\begin{array}{c}
\boldsymbol{\beta}_{1} \\
\vdots \\
\boldsymbol{\beta}_{N}
\end{array}\right]+\left[\begin{array}{c}
\mathbf{u}_{1} \\
\vdots \\
\mathbf{u}_{N}
\end{array}\right] \text { where } \boldsymbol{\beta}_{n}=\left(\alpha_{n}^{*},\left(\rho_{n}-1\right)\right)^{\prime}, n=1, \ldots, N,
$$

or more compactly, $\quad \nabla \tilde{\mathbf{Y}}_{t}=\tilde{\mathbf{Y}}_{t-1} \boldsymbol{\beta}+\mathbf{u}_{t}$.

The tests are then conducted as follows. 
i. Apply the ordinary least squares (OLS) to (2.2) and obtain the OLS residuals, $\tilde{u}_{t n}$ say.

ii. Calculate $\hat{\boldsymbol{\sigma}}_{N \times N}:=\sum_{t=1}^{T} \tilde{\mathbf{u}}_{t} \tilde{\mathbf{u}}_{t}^{\prime} / T$ where $\tilde{\mathbf{u}}_{t}=\left[\tilde{u}_{t 1} \ldots \tilde{u}_{t N}\right]^{\prime}$ and define $\mathbf{P}:=\left(\hat{\boldsymbol{\sigma}}^{-1 / 2} \otimes \mathbf{I}_{T}\right)$.

iii. Transform (2.9) by the pre multiplication: $\nabla \tilde{\mathbf{Y}}_{t}=\tilde{\mathbf{Y}}_{t-1} \boldsymbol{\beta}+\mathbf{u}_{t} \mapsto$ $\mathbf{P} \nabla \tilde{\mathbf{Y}}_{t}=\mathbf{P} \tilde{\mathbf{Y}}_{t-1} \boldsymbol{\beta}+\mathbf{P} \mathbf{u}_{t}$.

iv. Apply OLS to the transformed model and calculate the unrestricted residual sumof-square matrix $\mathbf{S}_{U}$ from the model $\mathbf{P} \nabla \mathbf{Y}_{t}=\mathbf{P} \mathbf{Y}_{t-1} \boldsymbol{\beta}+\mathbf{P} \mathbf{u}_{t}$ and calculate the restricted residual sum-of-square matrix $\mathbf{S}_{R}$ from the null model $\mathbf{P} \nabla \mathbf{Y}_{t}=\mathbf{P} \mathbf{u}_{t}$.

The $\mathbf{H}$ and $\mathbf{E}$ matrixes and the test statistics are then calculated as described above. In addition, note that this method readily extends to a model including which includes a constant term. When it comes to obtaining critical values at desired test level, these may be tabulated through simulations. However, that method is somewhat inconvenient, especially in a panel data context, since the tables would have to be constructed at two indexes (i.e. the number of cross sections and time observations respectively). An equivalent but more convenient method may be conducted through parametric bootstrap technique, described as follows.

Let $D\left(\mathbf{X}_{0}\right)$ be a test statistic, such as $T_{0}^{2}, V, \Lambda$ or $R$, calculated from an original sample $\mathbf{X}_{0}: T \times N$ (here $\mathbf{X}_{0}$ will represent $\nabla \mathbf{Y}_{t}$ ) and suppose that $B$ independent realizations of $\mathbf{X}_{0}$ (say $\left\{\mathbf{X}_{b}\right\}_{b=1}^{B}$ ) are available with distributions determined by $H_{0}$ and (2.1) with the corresponding test statistics $\left\{D\left(\mathbf{X}_{b}\right)\right\}_{b=1}^{B}$. The empirical $p$-values are then determined by

$$
\begin{aligned}
& \hat{p}_{B}\left(D\left(\mathbf{X}_{0}\right)\right)=\frac{B \hat{D}_{B}\left(\mathbf{X}_{0}\right)+1}{B+1} \text {, where } \\
& \hat{D}_{B}\left(\mathbf{X}_{0}\right)=B^{-1} \sum_{b=1}^{B} 1_{[0, \infty)}\left(D\left(\mathbf{X}_{b}\right)-D\left(\mathbf{X}_{0}\right)\right), \quad 1_{A}(\omega)=\left\{\begin{array}{l}
1, \text { if } \omega \in A \\
0, \text { if } \omega \notin A
\end{array}\right.
\end{aligned}
$$

Hence $\hat{D}_{B}\left(\mathbf{X}_{0}\right)$ is the proportion of times that $D_{B}\left(\mathbf{X}_{1}\right), \ldots, D_{B}\left(\mathbf{X}_{B}\right)$ exceeds $D\left(\mathbf{X}_{0}\right)$. The critical region of the test at significance level $\alpha$ is:

$$
\hat{p}_{B}\left(D\left(\mathbf{X}_{0}\right)\right) \leq \alpha .
$$

The null hypothesis of panel unit roots is rejected on the $\alpha$ level when the empirical $p$-value is less than $\alpha$. Hence, once this fairly simple algorithm is defined in appropriate software, there is no need for tabulated critical values for each $\{N, T\}$ pairing. 
To sum up the discussion so far, any of these four statistics may be used to test the hypothesis of the panel data unit root of (2.8) in a sense way that simultaneously allows cross-equation correlations and heterogeneous unit roots among the different units. Critical values and/or $p$ values may be obtained by tabulation of critical values or, preferably, by (2.11) to obtain empirical $p$-values, so that the tests are indeed feasible. But there is also an issue of the power properties of the tests, in particular when they are compared with other previously proposed tests for multivariate unit roots. The most commonly used test is probably that suggested by Im, Pesaran and Shin (2003) whose test statistic is formed by averaging individual (univariate) Dickey-Fuller $t$-test statistics. Their test can be described as follows. Let the $i$ th marginal model be determined by

$$
\Delta y_{i, t}=a_{i}+\rho_{i} y_{i, t-1}+u_{i, t},
$$

with the hypothesis

$$
\begin{aligned}
& H_{0}: \alpha_{i}=0 \forall_{i} \\
& H_{A}: \alpha_{i}<0 \exists_{\mathrm{i}}
\end{aligned} .
$$

The test statistic proposed by Im, Pesaran and Shin (2003) (IPS test) is then $\bar{t}_{N T}=N^{-1 / 2} \sum_{i=1}^{N} t_{i T}\left(p_{i}, \rho_{i}\right)$ where $t_{i T}\left(p_{i}, \rho_{i}\right)$ is the $i$ th individual (marginal) Dickey Fuller $t$-test statistic for testing $\rho_{i}=0$. Under the restriction of cross-sectional independence, the authors also derive the asymptotical distribution of the test with $Z=\sqrt{N}\left(\bar{t}_{N T}-E\left[t_{i T}\right]\right)\left(\operatorname{Vart}_{i T}\right)^{-1 / 2} \stackrel{\ell}{\rightarrow} N(0,1)$ as $T, N \rightarrow \infty$, and $E\left[t_{i T}\right]$ and $\sqrt{\operatorname{Vart}_{i T}}$ are tabulated by Monte Carlo experiments.

Where there is cross-sectional dependency, an alternative to the IPS test is the CIPS test proposed by Pesaran (2007). However, it should be noted that the CIPS test was proposed under the assumption that the cross-sectional dependency occurs due to a common factor affecting all of the variables in the panel, which may be a limitation of the test in cases where this assumption is not valid. But since these two tests are frequently used in applied analyses we will include them in the study.

The above tests, including the IPS/CIPS tests, could also be extended to allow for serially correlated errors, but here we will restrict ourselves to model (2.8) since there are already a substantial number of parameters in the model.

\section{The Monte Carlo simulations}


In this section we will present the data-generating process and outcomes of the experiments. The data will be generated according to the following model.

$$
\mathbf{Y}_{t}=\mathbf{a}^{*}+\boldsymbol{\rho} \mathbf{Y}_{t-1}+\boldsymbol{\Sigma}^{1 / 2} \mathbf{u}_{t}, \quad t=1, \ldots T
$$

where $\mathbf{u}_{t}: N \times 1$ is an error term. In order to obtain the appropriate properties of the process, it has been simulated with $T+200$ observations and then the first 200 start-up values have been deleted. $\mathbf{Y}_{t}: N \times 1$ is then a vector, consisting of variables that are integrated of order 1, i.e. I(1), if the coefficients $\rho_{i i}$ equals one and $\mathbf{a}^{*}=\left(\left(1-\rho_{11}\right) a_{1}, \ldots,\left(1-\rho_{N N}\right) a_{N}\right)^{\prime}$. If $\rho_{i i}$ is less than one the corresponding marginal variable is stationary. Our main interest lies in settings where the number of variables is rather large relative to the number of observations. We therefore use models consisting of $N \in\{5,10,15,20\}$ and $T \in\{30,50,100,200,500\}$. These combinations of $N$ and $T$ include cases when the number of variables is comparable to the number of observations as well as the large sample cases (i.e. when $T \gg N$ ). We set $\rho_{11}=\ldots=\rho_{N N}=1$ when the size is calculated, while for the power calculations the vector $\left(\rho_{11}, \ldots, \rho_{N N}\right)$ will be less than unity for some or all marginal variables. This will be done by using values relatively close to the null values (0.95 and 0.9 respectively). Moreover, since we are testing unit roots from a systemwize perspective, we will consider power simulations where all $N$ marginal variables are stationary as well as cases when only a portion of the variables ( $\pi$, say) is stationary. Specifically, we will consider $\pi \in\{1,0.6,0.2\}$. In addition, in order to impose cross dependencies we will generate the error term through the relation $\mathbf{u}_{t}=\mathbf{L} \boldsymbol{\eta}$ where $\boldsymbol{\eta} \square \operatorname{iidN}(\mathbf{0}, \mathbf{I}), \mathbf{L L}^{\prime}=\boldsymbol{\Sigma}$ and $\boldsymbol{\Sigma}$ is a circulant ${ }^{*}$ matrix. This format allows for determining covariance matrixes in a high-dimensional space without having to set every $\sigma_{i j}$ individually. (Note that none of the proposed test statistics (2.4) - (2.7) depends on this specific functional form of the covariance matrix. This form is merely used to conveniently generate a general, non-scalar psd covariance matrix.)

The following parameter settings generate positive definite covariance matrixes.

$$
\begin{aligned}
& \Sigma_{5 \times 5}=\operatorname{circ}(1,0.7,0.5,0.3,0.1) \\
& \Sigma_{10 \times 10}=\operatorname{circ}(1,0.7,0.6,0.5,0.4,0.3,0.2,0.1,0.05,0.01) \\
& \Sigma_{10 \times 10}=\operatorname{circ}(1,0.7,0.65,0.6,0.55,0.5,0.45,0.4,0.35,0.3,0.25,0.2,0.15,0.1,0.05) \\
& \Sigma_{20 \times 20}=\operatorname{circ}(1,0.7,0.65,0.6,0.55,0.5,0.45,0.4,0.35,0.3,0.3,0.25,0.25,0.2,0.2,0.15,0.15,0.1,0.1,0.05,0.05)
\end{aligned}
$$


"The circulant class matrixes used here have the form of $\operatorname{circ}\left(\begin{array}{lll}a_{1} & a_{2} & a_{3}\end{array}\right)=\left(\begin{array}{ccc}a_{1} & a_{2} & a_{3} \\ a_{2} & a_{1} & a_{2} \\ a_{3} & a_{2} & a_{1}\end{array}\right)$.

In order to evaluate the size of the tests, the following confidence interval is calculated.

$$
\alpha_{0} \pm 2 \frac{\sqrt{\alpha_{0}\left(1-\alpha_{0}\right)}}{M}
$$

where $M$ is the number of Monte Carlo replications (equal to 10,000) and $\alpha_{0}$ is the nominal size which is equal to 0.05 . The number of replicates used to determine the critical region (2.1) is set to 30,000 .

\section{Results}

In our Monte Carlo study we calculate the estimated size by simply observing how many times the null is rejected in repeated samples under conditions where the null is true. By varying factors like those described in the previous section, we can obtain a succession of estimated sizes under different conditions. In general, the closer an estimated size is to the nominal size the better we consider a test to be. In this section the results from the Monte Carlo experiment are presented. The estimated sizes of the tests are presented in Table 1. The confidence interval in equation (3.2) is doubled in magnitude in order to emphasize the pattern of well-performing tests more clearly. Therefore, if the actual size of a test exhibits a rejection frequency significantly below 0.06 it is considered as fair, which is marked out as shaded cells in the tables (here we do not consider low type-I error as a weakness of the test).

\subsection{Analysis of the Estimated Size}

The sizes of the different unit root tests are presented in Table 1. The statistical tests have fair size properties in the absence of cross-sectional dependency, which is expected since it is under this circumstance that the new critical values are generated. When adding some crosssectional dependency, the estimated type-I errors of the IPS and CIPS tests increase extremely. The results from our study indicate that the CIPS test may not account for a nonhomogeneous cross-sectional dependency. The actual size does not converge toward the nominal size either, so even in large samples one should be careful when applying the IPS and 
CIPS tests. Hence, pre-tests of correlation should always be used before applying any of these tests. The Lawley-Hotelling trace, Pillai's trace, Wilk's lambda and Rao's multivariate F-test $\left(T_{0}, \Lambda, V\right.$ and $\left.R\right)$ are much more robust, and they are almost always unbiased. In particular, when looking at the size of the tests, the $V$ test has shown to be very robust in all studied cases and hence should be the preferred option.

\subsection{Analysis of the Estimated Power}

The analysis of the power of the test is of central importance, since a test will be of little use if it does not have enough power to reject a false null hypothesis. Even if a correctly given size is a necessary prerequisite to ensure the good performance of a test, the tests should have enough power to reject a false null hypothesis. In our tables, however, we presented the power functions for all the tests though we put cross on the power results for the test with sever overrejection of the size. In this section we discuss the most interesting results of our Monte Carlo experiment; those concerning the power of the various versions of the tests. The power functions were estimated by calculating the rejection frequencies in 10,000 replications when $100 \%, 60 \%$ and $20 \%$ of the time series are stationary, according to the settings described in the previous section. The results of the power calculations are presented in Tables 2 to 4 . In Tables $2 \mathrm{a}$ and $2 \mathrm{~b}$, we present the results of the power functions in the cases when $100 \%$ of the time series are stationary for $\rho=0.90$ and 0.95 , respectively. For the cases when $60 \%$ and $20 \%$ of the time series are stationary, the results are presented in Tables $3 \mathrm{a}$ and $3 \mathrm{~b}$, and $4 \mathrm{a}$ and $4 \mathrm{~b}$ respectively.

The tables show that the power functions satisfy the expected properties of increasing with the sample size and the percentage of the stationary time series in the data. The power decreases, however, when the number of equations, and the strength of dependency among the equations, increases. The power functions are very low in small samples and large numbers of equations. In cases when $20 \%$ of the time series are stationary and small samples there is very little difference between the estimated size and the estimated power.

For the IPS and CIPS tests, introducing cross-sectional dependency also has an impact on the power properties of the tests. However, due to the fact that these tests are not robust in this situation and have improper sizes, the results of the power should not be considered any more 
in the analysis. In situations where there is cross-sectional dependency, the LM test should be preferred since, in general, it has the highest power among the tests for unit roots. 
Table 1: Sizes of the tests

\begin{tabular}{|c|c|c|c|c|c|c|c|c|c|c|c|c|}
\hline & \multicolumn{6}{|c|}{ Uncorrelated error terms } & \multicolumn{6}{|c|}{ Cross-correlated error terms } \\
\hline & \multicolumn{12}{|c|}{$\mathrm{N}=5$} \\
\hline $\mathrm{T}$ & IPS & CIPS & $T_{0}$ & $\Lambda$ & $V$ & $R$ & IPS & CIPS & $T_{0}$ & $\Lambda$ & $V$ & $R$ \\
\hline 30 & 0.048 & 0.048 & 0.051 & 0.050 & 0.048 & 0.050 & 0.106 & 0.194 & 0.059 & 0.059 & 0.057 & 0.059 \\
\hline 50 & 0.050 & 0.049 & 0.049 & 0.049 & 0.049 & 0.049 & 0.106 & 0.215 & 0.053 & 0.054 & 0.055 & 0.054 \\
\hline 100 & 0.051 & 0.052 & 0.049 & 0.048 & 0.050 & 0.048 & 0.114 & 0.232 & 0.055 & 0.057 & 0.057 & 0.057 \\
\hline 200 & 0.048 & 0.047 & 0.052 & 0.052 & 0.051 & 0.052 & 0.109 & 0.230 & 0.059 & 0.059 & 0.058 & 0.059 \\
\hline 500 & 0.051 & 0.050 & 0.053 & 0.052 & 0.052 & 0.052 & 0.110 & 0.230 & 0.060 & 0.059 & 0.059 & 0.059 \\
\hline $\mathrm{T}$ & \multicolumn{12}{|c|}{$\mathrm{N}=10$} \\
\hline 30 & 0.051 & 0.048 & 0.061 & 0.062 & 0.058 & 0.062 & 0.144 & 0.242 & 0.051 & 0.047 & 0.051 & 0.047 \\
\hline 50 & 0.045 & 0.049 & 0.045 & 0.045 & 0.052 & 0.045 & 0.148 & 0.264 & 0.059 & 0.057 & 0.060 & 0.057 \\
\hline 100 & 0.048 & 0.056 & 0.049 & 0.049 & 0.047 & 0.049 & 0.145 & 0.261 & 0.061 & 0.062 & 0.063 & 0.062 \\
\hline 200 & 0.055 & 0.049 & 0.058 & 0.058 & 0.055 & 0.058 & 0.153 & 0.280 & 0.060 & 0.060 & 0.060 & 0.060 \\
\hline 500 & 0.055 & 0.055 & 0.055 & 0.056 & 0.056 & 0.056 & 0.158 & 0.284 & 0.069 & 0.069 & 0.069 & 0.069 \\
\hline $\mathrm{T}$ & \multicolumn{12}{|c|}{$\mathrm{N}=15$} \\
\hline 30 & 0.050 & 0.049 & 0.048 & 0.045 & 0.048 & 0.045 & 0.196 & 0.312 & 0.061 & 0.037 & 0.052 & 0.037 \\
\hline 50 & 0.052 & 0.053 & 0.051 & 0.050 & 0.051 & 0.050 & 0.202 & 0.318 & 0.055 & 0.048 & 0.054 & 0.048 \\
\hline 100 & 0.048 & 0.052 & 0.055 & 0.054 & 0.053 & 0.005 & 0.199 & 0.338 & 0.059 & 0.060 & 0.062 & 0.007 \\
\hline 200 & 0.046 & 0.047 & 0.043 & 0.043 & 0.045 & 0.043 & 0.193 & 0.338 & 0.057 & 0.058 & 0.059 & 0.058 \\
\hline 500 & 0.051 & 0.054 & 0.050 & 0.050 & 0.050 & 0.050 & 0.204 & 0.352 & 0.068 & 0.069 & 0.070 & 0.069 \\
\hline $\mathrm{T}$ & \multicolumn{12}{|c|}{$\mathrm{N}=20$} \\
\hline 30 & 0.051 & 0.053 & 0.049 & 0.050 & 0.046 & 0.050 & 0.208 & 0.299 & 0.085 & 0.029 & 0.046 & 0.029 \\
\hline 50 & 0.047 & 0.047 & 0.047 & 0.047 & 0.048 & 0.047 & 0.207 & 0.317 & 0.053 & 0.037 & 0.047 & 0.037 \\
\hline 100 & 0.049 & 0.050 & 0.050 & 0.050 & 0.049 & 0.050 & 0.212 & 0.335 & 0.050 & 0.048 & 0.053 & 0.048 \\
\hline 200 & 0.052 & 0.047 & 0.050 & 0.050 & 0.052 & 0.050 & 0.203 & 0.330 & 0.064 & 0.064 & 0.060 & 0.064 \\
\hline 500 & 0.051 & 0.050 & 0.050 & 0.050 & 0.050 & 0.050 & 0.208 & 0.335 & 0.064 & 0.066 & 0.067 & 0.066 \\
\hline
\end{tabular}

Table 2a: Power when $100 \%$ of the time series are stationary where $\rho=0.90$

\begin{tabular}{|c|c|c|c|c|c|c|c|c|c|c|c|c|}
\hline & \multicolumn{6}{|c|}{ Uncorrelated error terms } & \multicolumn{6}{|c|}{ Cross-correlated error terms } \\
\hline & \multicolumn{12}{|c|}{$\mathrm{N}=5$} \\
\hline $\mathrm{T}$ & IPS & CIPS & $T_{0}$ & $\Lambda$ & $V$ & $R$ & IPS & CIPS & $T_{0}$ & $\Lambda$ & $V$ & $R$ \\
\hline 30 & 0.198 & 0.209 & 0.124 & 0.151 & 0.172 & 0.151 & $\mathrm{x}$ & $\mathrm{x}$ & 0.139 & 0.165 & 0.186 & 0.165 \\
\hline 50 & 0.471 & 0.477 & 0.319 & 0.354 & 0.390 & 0.354 & $\mathrm{x}$ & $\mathrm{x}$ & 0.333 & 0.369 & 0.406 & 0.369 \\
\hline 100 & 0.975 & 0.963 & 0.919 & 0.929 & 0.939 & 0.929 & $\mathrm{x}$ & $\mathrm{x}$ & 0.922 & 0.934 & 0.941 & 0.934 \\
\hline 200 & 1.000 & 1.000 & 1.000 & 1.000 & 1.000 & 1.000 & $\mathrm{x}$ & $\mathrm{x}$ & 1.000 & 1.000 & 1.000 & 1.000 \\
\hline 500 & 1.000 & 1.000 & 1.000 & 1.000 & 1.000 & 1.000 & $\mathrm{x}$ & $\mathrm{x}$ & 1.000 & 1.000 & 1.000 & 1.000 \\
\hline $\mathrm{T}$ & \multicolumn{12}{|c|}{$\mathrm{N}=10$} \\
\hline 30 & 0.374 & 0.395 & $\mathrm{x}$ & $\mathrm{x}$ & 0.279 & 0.220 & $\mathrm{x}$ & $\mathrm{x}$ & 0.137 & 0.211 & 0.261 & 0.211 \\
\hline 50 & 0.777 & 0.787 & 0.445 & 0.552 & 0.620 & 0.552 & $\mathrm{x}$ & $\mathrm{x}$ & 0.467 & 0.565 & 0.615 & 0.565 \\
\hline 100 & 1.000 & 1.000 & 0.996 & 0.998 & 0.998 & 0.998 & $\mathrm{x}$ & $\mathrm{x}$ & 0.997 & 0.997 & 0.998 & 0.997 \\
\hline 200 & 1.000 & 1.000 & 1.000 & 1.000 & 1.000 & 1.000 & $\mathrm{x}$ & $\mathrm{x}$ & 1.000 & 1.000 & 1.000 & 1.000 \\
\hline 500 & 1.000 & 1.000 & 1.000 & 1.000 & 1.000 & 1.000 & $\mathrm{x}$ & $\mathrm{x}$ & $\mathrm{x}$ & $\mathrm{x}$ & $\mathrm{x}$ & $\mathrm{x}$ \\
\hline $\mathrm{T}$ & \multicolumn{12}{|c|}{$\mathrm{N}=15$} \\
\hline 30 & 0.504 & 0.530 & 0.105 & 0.227 & 0.275 & 0.227 & $\mathrm{x}$ & $\mathrm{x}$ & 0.125 & 0.201 & 0.238 & 0.201 \\
\hline 50 & 0.926 & 0.924 & 0.483 & 0.663 & 0.741 & 0.663 & $\mathrm{x}$ & $\mathrm{x}$ & 0.481 & 0.633 & 0.640 & 0.633 \\
\hline 100 & 1.000 & 1.000 & 1.000 & 1.000 & 1.000 & 0.994 & $\mathrm{x}$ & $\mathrm{x}$ & 1.000 & 1.000 & 1.000 & 0.993 \\
\hline 200 & 1.000 & 1.000 & 1.000 & 1.000 & 1.000 & 1.000 & $\mathrm{x}$ & $\mathrm{x}$ & 1.000 & 1.000 & 1.000 & 1.000 \\
\hline 500 & 1.000 & 1.000 & 1.000 & 1.000 & 1.000 & 1.000 & $\mathrm{x}$ & $\mathrm{x}$ & $\mathrm{x}$ & $\mathrm{x}$ & $\mathrm{x}$ & $\mathrm{x}$ \\
\hline $\mathrm{T}$ & \multicolumn{12}{|c|}{$\mathrm{N}=20$} \\
\hline 30 & 0.635 & 0.643 & 0.067 & 0.228 & 0.202 & 0.228 & $\mathrm{x}$ & $\mathrm{x}$ & $\mathrm{x}$ & 0.166 & 0.139 & 0.166 \\
\hline 50 & 0.978 & 0.973 & 0.464 & 0.710 & 0.749 & 0.710 & $\mathrm{x}$ & $\mathrm{x}$ & 0.468 & 0.650 & 0.582 & 0.650 \\
\hline 100 & 1.000 & 1.000 & 1.000 & 1.000 & 1.000 & 1.000 & $\mathrm{x}$ & $\mathrm{x}$ & 1.000 & 1.000 & 1.000 & 1.000 \\
\hline 200 & 1.000 & 1.000 & 1.000 & 1.000 & 1.000 & 1.000 & $\mathrm{x}$ & $\mathrm{x}$ & $\mathrm{x}$ & $\mathrm{x}$ & 1.000 & $\mathrm{x}$ \\
\hline 500 & 1.000 & 1.000 & 1.000 & 1.000 & 1.000 & 1.000 & $\mathrm{x}$ & $\mathrm{x}$ & $\mathrm{x}$ & $\mathrm{x}$ & $\mathrm{x}$ & $\mathrm{x}$ \\
\hline
\end{tabular}


Table 2b: Power when $100 \%$ of the time series are stationary where $\rho=0.95$

\begin{tabular}{|c|c|c|c|c|c|c|c|c|c|c|c|c|}
\hline & \multicolumn{6}{|c|}{ Uncorrelated error terms } & \multicolumn{6}{|c|}{ Cross-correlated error terms } \\
\hline & \multicolumn{12}{|c|}{$\mathrm{N}=5$} \\
\hline $\mathrm{T}$ & IPS & CIPS & $T_{0}$ & $\Lambda$ & $V$ & $R$ & IPS & CIPS & $T_{0}$ & $\Lambda$ & $V$ & $R$ \\
\hline 30 & 0.097 & 0.098 & 0.073 & 0.083 & 0.087 & 0.083 & $\mathrm{x}$ & $\mathrm{x}$ & 0.084 & 0.094 & 0.104 & 0.094 \\
\hline 50 & 0.162 & 0.170 & 0.114 & 0.125 & 0.139 & 0.125 & $\mathrm{x}$ & $\mathrm{x}$ & 0.130 & 0.141 & 0.154 & 0.141 \\
\hline 100 & 0.457 & 0.462 & 0.352 & 0.368 & 0.384 & 0.368 & $\mathrm{x}$ & $\mathrm{x}$ & 0.363 & 0.380 & 0.397 & 0.380 \\
\hline 200 & 0.973 & 0.961 & 0.931 & 0.935 & 0.938 & 0.935 & $\mathrm{x}$ & $\mathrm{x}$ & 0.939 & 0.944 & 0.948 & 0.944 \\
\hline 500 & 1.000 & 1.000 & 1.000 & 1.000 & 1.000 & 1.000 & $\mathrm{x}$ & $\mathrm{x}$ & 1.000 & 1.000 & 1.000 & 1.000 \\
\hline $\mathrm{T}$ & \multicolumn{12}{|c|}{$\mathrm{N}=10$} \\
\hline 30 & 0.145 & 0.157 & 0.074 & 0.104 & 0.121 & 0.104 & $\mathrm{x}$ & $\mathrm{x}$ & 0.086 & 0.102 & 0.126 & 0.102 \\
\hline 50 & 0.272 & 0.296 & 0.152 & 0.183 & 0.211 & 0.183 & $\mathrm{x}$ & $\mathrm{x}$ & 0.162 & 0.198 & 0.234 & 0.198 \\
\hline 100 & 0.773 & 0.785 & 0.560 & 0.603 & 0.637 & 0.603 & $\mathrm{x}$ & $\mathrm{x}$ & 0.585 & 0.628 & 0.663 & 0.628 \\
\hline 200 & 0.820 & 0.820 & 0.817 & 0.817 & 0.818 & 0.817 & $\mathrm{x}$ & $\mathrm{x}$ & 0.998 & 0.999 & 0.999 & 0.999 \\
\hline 500 & 1.000 & 1.000 & 1.000 & 1.000 & 1.000 & 1.000 & $\mathrm{x}$ & $\mathrm{X}$ & $\mathrm{X}$ & $\mathrm{x}$ & $\mathrm{X}$ & $\mathrm{x}$ \\
\hline $\mathrm{T}$ & \multicolumn{12}{|c|}{$\mathrm{N}=15$} \\
\hline 30 & 0.185 & 0.195 & 0.069 & 0.110 & 0.131 & 0.110 & $\mathrm{x}$ & $\mathrm{x}$ & 0.084 & 0.093 & 0.117 & 0.093 \\
\hline 50 & 0.378 & 0.407 & 0.164 & 0.227 & 0.270 & 0.227 & $\mathrm{x}$ & $\mathrm{X}$ & 0.169 & 0.220 & 0.254 & 0.220 \\
\hline 100 & 0.921 & 0.923 & 0.690 & 0.749 & 0.791 & 0.350 & $\mathrm{x}$ & $\mathrm{X}$ & 0.700 & 0.753 & 0.784 & 0.358 \\
\hline 200 & 1.000 & 1.000 & 1.000 & 1.000 & 1.000 & 1.000 & $\mathrm{X}$ & $\mathrm{x}$ & 1.000 & 1.000 & 1.000 & 1.000 \\
\hline 500 & 1.000 & 1.000 & 1.000 & 1.000 & 1.000 & 1.000 & $\mathrm{x}$ & $\mathrm{x}$ & $\mathrm{X}$ & $\mathrm{X}$ & $\mathrm{X}$ & $\mathrm{x}$ \\
\hline $\mathrm{T}$ & \multicolumn{12}{|c|}{$\mathrm{N}=20$} \\
\hline 30 & 0.228 & 0.235 & 0.055 & 0.106 & 0.106 & 0.106 & $\mathrm{x}$ & $\mathrm{x}$ & $\mathrm{x}$ & 0.072 & 0.088 & 0.072 \\
\hline 50 & 0.497 & 0.503 & 0.160 & 0.265 & 0.299 & 0.265 & $\mathrm{x}$ & $\mathrm{x}$ & 0.168 & 0.213 & 0.227 & 0.213 \\
\hline 100 & 0.975 & 0.974 & 0.748 & 0.831 & 0.874 & 0.831 & $\mathrm{x}$ & $\mathrm{x}$ & 0.773 & 0.838 & 0.852 & 0.838 \\
\hline 200 & 1.000 & 1.000 & 1.000 & 1.000 & 1.000 & 1.000 & $\mathrm{x}$ & $\mathrm{x}$ & $\mathrm{X}$ & $\mathrm{x}$ & 1.000 & $\mathrm{x}$ \\
\hline 500 & 1.000 & 1.000 & 1.000 & 1.000 & 1.000 & 1.000 & $\mathrm{x}$ & $\mathrm{x}$ & $\mathrm{x}$ & $\mathrm{x}$ & $\mathrm{X}$ & $\mathrm{x}$ \\
\hline
\end{tabular}

Table 3a: Power when $60 \%$ of the time series are stationary where $\rho=0.90$

\begin{tabular}{|c|c|c|c|c|c|c|c|c|c|c|c|c|}
\hline & \multicolumn{6}{|c|}{ Uncorrelated error terms } & \multicolumn{6}{|c|}{ Cross-correlated error terms } \\
\hline & \multicolumn{12}{|c|}{$\mathrm{N}=5$} \\
\hline $\mathrm{T}$ & IPS & CIPS & $T_{0}$ & $\Lambda$ & $V$ & $R$ & IPS & CIPS & $T_{0}$ & $\Lambda$ & $V$ & $R$ \\
\hline 30 & 0.120 & 0.124 & 0.092 & 0.103 & 0.108 & 0.103 & $\mathrm{x}$ & $\mathrm{x}$ & 0.103 & 0.108 & 0.113 & 0.108 \\
\hline 50 & 0.226 & 0.226 & 0.170 & 0.184 & 0.197 & 0.184 & $\mathrm{x}$ & $\mathrm{X}$ & 0.228 & 0.234 & 0.240 & 0.234 \\
\hline 100 & 0.577 & 0.599 & 0.568 & 0.572 & 0.580 & 0.572 & $\mathrm{x}$ & $\mathrm{x}$ & 0.745 & 0.743 & 0.741 & 0.743 \\
\hline 200 & 0.968 & 0.980 & 0.995 & 0.996 & 0.995 & 0.996 & $\mathrm{x}$ & $\mathrm{x}$ & 1.000 & 1.000 & 1.000 & 1.000 \\
\hline 500 & 1.000 & 1.000 & 1.000 & 1.000 & 1.000 & 1.000 & $\mathrm{x}$ & $\mathrm{x}$ & 1.000 & 1.000 & 1.000 & 1.000 \\
\hline $\mathrm{T}$ & \multicolumn{12}{|c|}{$\mathrm{N}=10$} \\
\hline 30 & 0.187 & 0.196 & 0.091 & 0.129 & 0.148 & 0.129 & $\mathrm{x}$ & $\mathrm{x}$ & 0.112 & 0.131 & 0.143 & 0.131 \\
\hline 50 & 0.360 & 0.381 & 0.228 & 0.272 & 0.301 & 0.272 & $\mathrm{x}$ & $\mathrm{x}$ & 0.282 & 0.314 & 0.329 & 0.314 \\
\hline 100 & 0.858 & 0.861 & 0.820 & 0.837 & 0.846 & 0.837 & $\mathrm{x}$ & $\mathrm{x}$ & 0.908 & 0.913 & 0.912 & 0.913 \\
\hline 200 & 1.000 & 1.000 & 1.000 & 1.000 & 1.000 & 1.000 & $\mathrm{x}$ & $\mathrm{x}$ & 1.000 & 1.000 & 1.000 & 1.000 \\
\hline 500 & 1.000 & 1.000 & 1.000 & 1.000 & 1.000 & 1.000 & $\mathrm{x}$ & $\mathrm{X}$ & $\mathrm{X}$ & $\mathrm{X}$ & $\mathrm{X}$ & $\mathrm{X}$ \\
\hline $\mathrm{T}$ & \multicolumn{12}{|c|}{$\mathrm{N}=15$} \\
\hline 30 & 0.228 & 0.245 & 0.074 & 0.121 & 0.139 & 0.121 & $\mathrm{x}$ & $\mathrm{x}$ & 0.112 & 0.117 & 0.119 & 0.117 \\
\hline 50 & 0.503 & 0.523 & 0.252 & 0.340 & 0.367 & 0.340 & $\mathrm{x}$ & $\mathrm{x}$ & 0.312 & 0.350 & 0.327 & 0.350 \\
\hline 100 & 0.958 & 0.965 & 0.923 & 0.938 & 0.940 & 0.664 & $\mathrm{x}$ & $\mathrm{x}$ & 0.964 & 0.969 & 0.959 & 0.785 \\
\hline 200 & 1.000 & 1.000 & 1.000 & 1.000 & 1.000 & 1.000 & $\mathrm{x}$ & $\mathrm{x}$ & 1.000 & 1.000 & 1.000 & 1.000 \\
\hline 500 & 1.000 & 1.000 & 1.000 & 1.000 & 1.000 & 1.000 & $\mathrm{x}$ & $\mathrm{x}$ & $\mathrm{x}$ & $\mathrm{X}$ & $\mathrm{X}$ & $\mathrm{X}$ \\
\hline $\mathrm{T}$ & \multicolumn{12}{|c|}{$\mathrm{N}=20$} \\
\hline 30 & 0.295 & 0.301 & 0.067 & 0.133 & 0.113 & 0.133 & $\mathrm{x}$ & $\mathrm{x}$ & $\mathrm{X}$ & 0.094 & 0.070 & 0.094 \\
\hline 50 & 0.621 & 0.618 & 0.247 & 0.371 & 0.378 & 0.371 & $\mathrm{x}$ & $\mathrm{X}$ & 0.305 & 0.339 & 0.276 & 0.339 \\
\hline 100 & 0.991 & 0.990 & 0.955 & 0.968 & 0.969 & 0.968 & $\mathrm{x}$ & $\mathrm{x}$ & 0.981 & 0.982 & 0.967 & 0.982 \\
\hline 200 & 1.000 & 1.000 & 1.000 & 1.000 & 1.000 & 1.000 & $\mathrm{x}$ & $\mathrm{x}$ & $\mathrm{x}$ & $\mathrm{x}$ & 1.000 & $\mathrm{x}$ \\
\hline 500 & 1.000 & 1.000 & 1.000 & 1.000 & 1.000 & 1.000 & $\mathrm{x}$ & $\mathrm{x}$ & $\mathrm{X}$ & $\mathrm{X}$ & $\mathrm{X}$ & $\mathrm{x}$ \\
\hline
\end{tabular}


Table 3b: Power when $60 \%$ of the time series are stationary where $\rho=0.95$

\begin{tabular}{|c|c|c|c|c|c|c|c|c|c|c|c|c|}
\hline & \multicolumn{6}{|c|}{ Uncorrelated error terms } & \multicolumn{6}{|c|}{ Cross-correlated error terms } \\
\hline & \multicolumn{12}{|c|}{$\mathrm{N}=5$} \\
\hline $\mathrm{T}$ & IPS & CIPS & $T_{0}$ & $\Lambda$ & $V$ & $R$ & IPS & CIPS & $T_{0}$ & $\Lambda$ & $V$ & $R$ \\
\hline 30 & 0.077 & 0.077 & 0.067 & 0.071 & 0.074 & 0.071 & $\mathrm{x}$ & $\mathrm{x}$ & 0.068 & 0.073 & 0.078 & 0.073 \\
\hline 50 & 0.097 & 0.102 & 0.079 & 0.082 & 0.086 & 0.082 & $\mathrm{x}$ & $\mathrm{x}$ & 0.104 & 0.107 & 0.109 & 0.107 \\
\hline 100 & 0.215 & 0.219 & 0.183 & 0.187 & 0.195 & 0.187 & $\mathrm{x}$ & $\mathrm{x}$ & 0.104 & 0.107 & 0.109 & 0.107 \\
\hline 200 & 0.568 & 0.576 & 0.569 & 0.574 & 0.578 & 0.574 & $\mathrm{x}$ & $\mathrm{x}$ & 0.766 & 0.766 & 0.763 & 0.766 \\
\hline 500 & 0.993 & 0.998 & 1.000 & 1.000 & 1.000 & 1.000 & $\mathrm{x}$ & $\mathrm{x}$ & 1.000 & 1.000 & 1.000 & 1.000 \\
\hline $\mathrm{T}$ & \multicolumn{12}{|c|}{$\mathrm{N}=10$} \\
\hline 30 & 0.092 & 0.100 & 0.063 & 0.079 & 0.087 & 0.079 & $\mathrm{x}$ & $\mathrm{x}$ & 0.072 & 0.077 & 0.085 & 0.077 \\
\hline 50 & 0.151 & 0.159 & 0.105 & 0.120 & 0.131 & 0.120 & $\mathrm{x}$ & $\mathrm{x}$ & 0.118 & 0.132 & 0.144 & 0.132 \\
\hline 100 & 0.352 & 0.370 & 0.270 & 0.291 & 0.308 & 0.291 & $\mathrm{x}$ & $\mathrm{x}$ & 0.344 & 0.356 & 0.367 & 0.356 \\
\hline 200 & 0.844 & 0.848 & 0.837 & 0.841 & 0.846 & 0.841 & $\mathrm{x}$ & $\mathrm{x}$ & 0.919 & 0.920 & 0.921 & 0.920 \\
\hline 500 & 1.000 & 1.000 & 1.000 & 1.000 & 1.000 & 1.000 & $\mathrm{x}$ & $\mathrm{x}$ & $\mathrm{x}$ & $\mathrm{x}$ & $\mathrm{x}$ & $\mathrm{x}$ \\
\hline $\mathrm{T}$ & \multicolumn{12}{|c|}{$\mathrm{N}=15$} \\
\hline 30 & 0.117 & 0.125 & 0.061 & 0.085 & 0.091 & 0.085 & $\mathrm{x}$ & $\mathrm{x}$ & 0.074 & 0.060 & 0.074 & 0.060 \\
\hline 50 & 0.191 & 0.202 & 0.109 & 0.136 & 0.154 & 0.136 & $\mathrm{x}$ & $\mathrm{x}$ & 0.116 & 0.129 & 0.138 & 0.129 \\
\hline 100 & 0.498 & 0.512 & 0.359 & 0.392 & 0.413 & 0.105 & $\mathrm{x}$ & $\mathrm{x}$ & 0.434 & 0.457 & 0.462 & 0.137 \\
\hline 200 & 0.949 & 0.952 & 0.943 & 0.948 & 0.951 & 0.948 & $\mathrm{x}$ & $\mathrm{x}$ & 0.978 & 0.978 & 0.978 & 0.978 \\
\hline 500 & 1.000 & 1.000 & 1.000 & 1.000 & 1.000 & 1.000 & $\mathrm{x}$ & $\mathrm{x}$ & $\mathrm{x}$ & $\mathrm{x}$ & $\mathrm{x}$ & $\mathrm{x}$ \\
\hline $\mathrm{T}$ & \multicolumn{12}{|c|}{$\mathrm{N}=20$} \\
\hline 30 & 0.136 & 0.133 & 0.056 & 0.081 & 0.080 & 0.081 & $\mathrm{x}$ & $\mathrm{x}$ & $\mathrm{x}$ & 0.053 & 0.057 & 0.053 \\
\hline 50 & 0.234 & 0.240 & 0.104 & 0.141 & 0.155 & 0.141 & $\mathrm{x}$ & $\mathrm{x}$ & 0.120 & 0.113 & 0.114 & 0.113 \\
\hline 100 & 0.621 & 0.613 & 0.401 & 0.459 & 0.493 & 0.459 & $\mathrm{x}$ & $\mathrm{x}$ & 0.466 & 0.499 & 0.496 & 0.499 \\
\hline 200 & 0.987 & 0.985 & 0.983 & 0.984 & 0.986 & 0.984 & $\mathrm{x}$ & $\mathrm{x}$ & $\mathrm{x}$ & $\mathrm{x}$ & 0.994 & $\mathrm{x}$ \\
\hline 500 & 1.000 & 1.000 & 1.000 & 1.000 & 1.000 & 1.000 & $\mathrm{x}$ & $\mathrm{x}$ & $\mathrm{x}$ & $\mathrm{x}$ & $\mathrm{x}$ & $\mathrm{x}$ \\
\hline
\end{tabular}

Table 4a: Power when $20 \%$ of the time series are stationary where $\rho=0.90$

\begin{tabular}{|c|c|c|c|c|c|c|c|c|c|c|c|c|}
\hline & \multicolumn{6}{|c|}{ Uncorrelated error terms } & \multicolumn{6}{|c|}{ Cross-correlated error terms } \\
\hline & \multicolumn{12}{|c|}{$\mathrm{N}=5$} \\
\hline $\mathrm{T}$ & IPS & CIPS & $T_{0}$ & $\Lambda$ & $V$ & $R$ & IPS & CIPS & Wald & LR & LM & Rao \\
\hline 30 & 0.065 & 0.062 & 0.060 & 0.061 & 0.063 & 0.061 & $\mathrm{x}$ & $\mathrm{x}$ & 0.071 & 0.070 & 0.069 & 0.070 \\
\hline 50 & 0.085 & 0.087 & 0.079 & 0.080 & 0.084 & 0.080 & $\mathrm{x}$ & $\mathrm{x}$ & 0.112 & 0.106 & 0.103 & 0.106 \\
\hline 100 & 0.134 & 0.141 & 0.146 & 0.145 & 0.146 & 0.145 & $\mathrm{x}$ & $\mathrm{x}$ & 0.314 & 0.296 & 0.280 & 0.296 \\
\hline 200 & 0.269 & 0.278 & 0.390 & 0.382 & 0.371 & 0.382 & $\mathrm{x}$ & $\mathrm{x}$ & 0.814 & 0.797 & 0.777 & 0.797 \\
\hline 500 & 0.652 & 0.681 & 0.980 & 0.977 & 0.974 & 0.977 & $\mathrm{x}$ & $\mathrm{x}$ & 1.000 & 1.000 & 1.000 & 1.000 \\
\hline $\mathrm{T}$ & \multicolumn{12}{|c|}{$\mathrm{N}=10$} \\
\hline 30 & 0.084 & 0.087 & 0.057 & 0.069 & 0.077 & 0.069 & $\mathrm{x}$ & $\mathrm{x}$ & 0.072 & 0.068 & 0.070 & 0.068 \\
\hline 50 & 0.106 & 0.110 & 0.092 & 0.099 & 0.105 & 0.099 & $\mathrm{x}$ & $\mathrm{x}$ & 0.126 & 0.126 & 0.122 & 0.126 \\
\hline 100 & 0.142 & 0.140 & 0.148 & 0.151 & 0.150 & 0.151 & $\mathrm{x}$ & $\mathrm{x}$ & 0.374 & 0.360 & 0.340 & 0.360 \\
\hline 200 & 0.438 & 0.433 & 0.631 & 0.615 & 0.596 & 0.615 & $\mathrm{x}$ & - & 0.901 & 0.885 & 0.866 & 0.885 \\
\hline 500 & 0.955 & 0.964 & 1.000 & 1.000 & 1.000 & 1.000 & $\mathrm{x}$ & $\mathrm{x}$ & $\mathrm{x}$ & $\mathrm{x}$ & $\mathrm{x}$ & $\mathrm{x}$ \\
\hline $\mathrm{T}$ & \multicolumn{12}{|c|}{$\mathrm{N}=15$} \\
\hline 30 & 0.092 & 0.094 & 0.064 & 0.071 & 0.073 & 0.071 & $\mathrm{x}$ & $\mathrm{x}$ & 0.082 & 0.057 & 0.057 & 0.057 \\
\hline 50 & 0.133 & 0.133 & 0.092 & 0.108 & 0.115 & 0.108 & $\mathrm{x}$ & $\mathrm{x}$ & 0.127 & 0.119 & 0.110 & 0.119 \\
\hline 100 & 0.261 & 0.263 & 0.271 & 0.277 & 0.276 & 0.062 & $\mathrm{x}$ & $\mathrm{x}$ & 0.452 & 0.425 & 0.390 & 0.131 \\
\hline 200 & 0.564 & 0.561 & 0.772 & 0.759 & 0.741 & 0.759 & $\mathrm{x}$ & $\mathrm{x}$ & 0.964 & 0.953 & 0.936 & 0.953 \\
\hline 500 & 0.974 & 0.974 & 1.000 & 1.000 & 1.000 & 1.000 & $\mathrm{x}$ & $\mathrm{x}$ & $\mathrm{x}$ & $\mathrm{x}$ & $\mathrm{x}$ & $\mathrm{x}$ \\
\hline $\mathrm{T}$ & \multicolumn{12}{|c|}{$\mathrm{N}=20$} \\
\hline 30 & 0.104 & 0.101 & 0.056 & 0.070 & 0.063 & 0.070 & $\mathrm{x}$ & $\mathrm{x}$ & $\mathrm{x}$ & 0.048 & 0.043 & 0.048 \\
\hline 50 & 0.152 & 0.150 & 0.095 & 0.115 & 0.108 & 0.115 & $\mathrm{x}$ & $\mathrm{x}$ & 0.130 & 0.106 & 0.088 & 0.106 \\
\hline 100 & 0.317 & 0.312 & 0.308 & 0.321 & 0.310 & 0.321 & $\mathrm{x}$ & $\mathrm{x}$ & 0.465 & 0.440 & 0.382 & 0.440 \\
\hline 200 & 0.684 & 0.645 & 0.874 & 0.860 & 0.837 & 0.860 & $\mathrm{x}$ & $\mathrm{x}$ & $\mathrm{x}$ & $\mathrm{x}$ & 0.959 & $\mathrm{x}$ \\
\hline 500 & 0.994 & 0.992 & 1.000 & 1.000 & 1.000 & 1.000 & $\mathrm{x}$ & $\mathrm{x}$ & $\mathrm{x}$ & $\mathrm{x}$ & $\mathrm{x}$ & $\mathrm{x}$ \\
\hline
\end{tabular}


Table 4b: Power when $20 \%$ of the time series are stationary where $\rho=0.95$

\begin{tabular}{|c|c|c|c|c|c|c|c|c|c|c|c|c|}
\hline & \multicolumn{6}{|c|}{ Uncorrelated error terms } & \multicolumn{6}{|c|}{ Cross-correlated error terms } \\
\hline & \multicolumn{12}{|c|}{$\mathrm{N}=5$} \\
\hline $\mathrm{T}$ & IPS & CIPS & $T_{0}$ & $\Lambda$ & $V$ & $R$ & IPS & CIPS & $T_{0}$ & $\Lambda$ & $V$ & $R$ \\
\hline 30 & 0.058 & 0.057 & 0.060 & 0.060 & 0.058 & 0.060 & $\mathrm{X}$ & $\mathrm{x}$ & 0.063 & 0.061 & 0.062 & 0.061 \\
\hline 50 & 0.065 & 0.064 & 0.058 & 0.059 & 0.060 & 0.059 & $\mathrm{X}$ & $\mathrm{x}$ & 0.071 & 0.069 & 0.070 & 0.069 \\
\hline 100 & 0.082 & 0.082 & 0.076 & 0.078 & 0.079 & 0.078 & $\mathrm{x}$ & $\mathrm{x}$ & 0.117 & 0.113 & 0.112 & 0.113 \\
\hline 200 & 0.140 & 0.144 & 0.151 & 0.152 & 0.150 & 0.152 & $\mathrm{x}$ & $\mathrm{x}$ & 0.317 & 0.310 & 0.299 & 0.310 \\
\hline 500 & 0.334 & 0.346 & 0.524 & 0.518 & 0.513 & 0.518 & $\mathrm{x}$ & $\mathrm{x}$ & 0.924 & 0.921 & 0.915 & 0.921 \\
\hline $\mathrm{T}$ & \multicolumn{12}{|c|}{$\mathrm{N}=10$} \\
\hline 30 & 0.068 & 0.070 & 0.053 & 0.058 & 0.064 & 0.058 & $\mathrm{x}$ & $\mathrm{X}$ & 0.063 & 0.057 & 0.060 & 0.057 \\
\hline 50 & 0.072 & 0.070 & 0.064 & 0.066 & 0.072 & 0.066 & $\mathrm{x}$ & $\mathrm{x}$ & 0.075 & 0.072 & 0.076 & 0.072 \\
\hline 100 & 0.105 & 0.108 & 0.097 & 0.099 & 0.100 & 0.099 & $\mathrm{x}$ & $\mathrm{X}$ & 0.137 & 0.136 & 0.132 & 0.136 \\
\hline 200 & 0.199 & 0.194 & 0.213 & 0.212 & 0.212 & 0.212 & $\mathrm{X}$ & $\mathrm{X}$ & 0.364 & 0.355 & 0.347 & 0.355 \\
\hline 500 & 0.708 & 0.728 & 0.908 & 0.913 & 0.920 & 0.911 & $\mathrm{x}$ & $\mathrm{X}$ & $\mathrm{X}$ & $\mathrm{X}$ & $\mathrm{X}$ & $\mathrm{X}$ \\
\hline $\mathrm{T}$ & \multicolumn{12}{|c|}{$\mathrm{N}=15$} \\
\hline 30 & 0.063 & 0.063 & 0.051 & 0.057 & 0.058 & 0.057 & $\mathrm{x}$ & $\mathrm{X}$ & 0.068 & 0.043 & 0.056 & 0.043 \\
\hline 50 & 0.081 & 0.084 & 0.060 & 0.069 & 0.073 & 0.069 & $\mathrm{x}$ & $\mathrm{x}$ & 0.070 & 0.064 & 0.070 & 0.064 \\
\hline 100 & 0.126 & 0.132 & 0.114 & 0.120 & 0.123 & 0.018 & $\mathrm{X}$ & $\mathrm{X}$ & 0.156 & 0.156 & 0.152 & 0.026 \\
\hline 200 & 0.249 & 0.251 & 0.264 & 0.265 & 0.266 & 0.265 & $\mathrm{x}$ & $\mathrm{x}$ & 0.458 & 0.446 & 0.434 & 0.446 \\
\hline 500 & 0.695 & 0.683 & 0.935 & 0.930 & 0.925 & 0.930 & $\mathrm{x}$ & $\mathrm{x}$ & $\mathrm{X}$ & $\mathrm{X}$ & $\mathrm{X}$ & $\mathrm{X}$ \\
\hline $\mathrm{T}$ & \multicolumn{12}{|c|}{$\mathrm{N}=20$} \\
\hline 30 & 0.069 & 0.069 & 0.052 & 0.058 & 0.059 & 0.058 & $\mathrm{X}$ & $\mathrm{x}$ & $\mathrm{X}$ & 0.032 & 0.044 & 0.032 \\
\hline 50 & 0.089 & 0.088 & 0.061 & 0.068 & 0.074 & 0.068 & $\mathrm{x}$ & $\mathrm{x}$ & 0.075 & 0.057 & 0.061 & 0.057 \\
\hline 100 & 0.145 & 0.153 & 0.113 & 0.122 & 0.128 & 0.122 & $\mathrm{x}$ & $\mathrm{x}$ & 0.153 & 0.154 & 0.148 & 0.154 \\
\hline 200 & 0.314 & 0.292 & 0.335 & 0.334 & 0.337 & 0.334 & $\mathrm{x}$ & $\mathrm{x}$ & $\mathrm{X}$ & $\mathrm{X}$ & 0.491 & $\mathrm{X}$ \\
\hline 500 & 0.792 & 0.767 & 0.975 & 0.972 & 0.969 & 0.972 & $\mathrm{X}$ & $\mathrm{x}$ & $\mathrm{x}$ & $\mathrm{x}$ & $\mathrm{x}$ & $\mathrm{x}$ \\
\hline
\end{tabular}

\section{Summary and Conclusions}

In this paper we propose four tests for unit roots from panel data perspectives. These tests are generalized from traditional multivariate tests for linear restrictions and have the properties of being valid even under unknown cross-sectional dependence, a property that is present in many real applications. In fact, the test statistics known as Hotellings trace, LawleyHotellings trace, Wilks lambda and Rao's multivariate $F$-test were developed in the early and mid-nineteen hundreds to deal with precisely these matters. The tests do not, in contrast to previously introduced panel data unit root tests, assume a common (homogeneous) unit root parameter in each marginal model or cross-sectional independence. Moreover, the fact that the test statistics are invariant under certain linear transformations, enables the use of Monte Carlo critical values so that there is no need to derive null distributions of the test statistics. Arbitrary size precision is therefore available through computer simulations. In these ways, the proposed tests are universally valid and rely on a minimum of distributional assumptions. However, before a new statistical method can be considered useful, its properties should be examined and contrasted to existing, previously proposed methods. In this perspective, we 
have conducted a Monte Carlo simulation of the four tests as well as the common tests labeled as IPS and CIPS respectively. A large number of models were investigated in the simulations, where the number of observations, the number of equations and the degree of dependency between equations were varied. For the power calculations, the deviation from the null hypothesis was varied through different percentages of stationary marginal variables and different sizes of the autoregressive parameter. The results have shown that IPS and CIPS are non-robust to cross-sectional dependency. These tests considerably over-reject the null hypothesis when it is true. The tests of Hotellings trace, Lawley-Hotellings trace, Wilks lambda and Rao's multivariate $F$-test are demonstrated to have stable size properties in the sense that they remain close to the nominal size even under heterogeneous alternatives and the presence of cross-correlations.

The power functions have been shown to increase with the sample size and the percentage of the stationary time series in the data, but decrease when the number of equations and strength of dependency among the equations increases, as expected. Since the IPS and CIPS tests do not have fair size properties, their power properties cannot be judged in an appropriate way under a general covariance matrix. However, in cases where the number of cross units $N$ is proportional to, or even exceeds, the number of observations $T$, some sorts of parameter restriction, such as those of the CIPS or IPS test, need to be imposed in order to obtain a consistent test. In other words, hypothesis testing of multivariate unit roots is concerned with a trade-off between on the one hand requiring high power in cases where $N$ and $T$ are proportional (which requires strong restrictions on the functional form of the covariance matrix and/or the unit root parameter matrix) and on the other hand requiring a test which remains well behaved under a general residual covariance matrix of unknown functional form. The conclusions of our paper are that in cases where the data-generating process is a priori known to follow a simple structure, such as a factor model or a diagonal covariance matrix, tests developed under such conditions will be the optimal choice. However, in more general contexts usage of these tests may be hazardous and should be abandoned in favor of multivariate tests. In particular, this paper shows that the Lawley-Hotelling trace test has the greatest size and power properties among other comparable tests and is hence the test to be recommended in real applications. 


\section{References}

Anderson, T. W. (2003), An Introduction to Multivariate Analysi, Wiley.

Bai, J. and Ng, S. (2004), 'A PANIC attack on unit roots and cointegration', Econometrica, vol 72: pp 1127-1177.

Bewley, R. (1986), 'Allocation models, Specification, Estimation and Applications', Cambridge, , Ballinger Publishing Company

Breitung, J. and Meyer, W. (1994), 'Testing for unit roots in panel data: Are wages on different bargaining levels cointegrated?' Applied Economics, vol 26: pp 353-361.

Choi, I. (2002), 'Instrumental variables estimation of a nearly nonstationary, heterogeneous error component model', Journal of Econometrics, vol 109: pp 1-32.

Dickey, D. and Fuller, W. (1979), 'Distribution of the estimators for autoregressive time series with a unit root', Journal of the American Statistical Association, vol 74: pp 427-431.

Edgerton, D. and Shukur, G. (1999), 'Testing autocorrelation in a system perspective', Econometric Reviews, vol 18(4): pp 343-386.

Fujikoshi, Y. (1970), 'Asymptotic expansions of the distributions of test statistics in multivariate analysis', Journal of Science of the Hiroshima University, series A-I. 34: 73144.

Fujikoshi, Y. (1988), 'Comparison of powers of a class of tests for mulivariate linear hypothesis and independence', Journal of Multivariate Analysis, vol 26: pp 48-58.

Fuller, W. (1996), Introduction to Statistical Time Series (second ed.). London?:Wiley.

Holgersson, H. E. T. (2004), 'Testing for multivariate autocorrelation', Journal of Applied Statistics, vol 4: pp 379-395.

Holgersson, H. E. T. and Shukur, G. (2004), 'Testing for multivariate heteroscedasticity', Journal of Statistical Computation and Simulation, vol 74(12): pp 879-896.

Im, K. S., Pesaran, M. H. and Shin, Y. (2003), 'Testing for unit roots in heterogeneous panels', Journal of Econometrics, vol 115: pp 53-74.

Judge, G. G., Griffiths, W. E., Hill, R. C., Lutkepohl, H. and Lee, T-C. (1985), The Theory and Practice of Econometrics, Wiley.

Hotelling, H. (1947), 'Multivariate quality control illustrated by the air testing of sample bombsights', Techniques of Statistical Analysis, Mcgraw-Hill.

Kibria, B. M. G. and A. K. MS. E. Saleh(2005), 'Pooling multivariate data under W, LR, and LM tests', Statistical Papers, vol 47: pp 49-68. [In the text. Kibria appears with Saleh. Is Kibria and Saleh (2005) another paper or is there a mistake here?]

Lawley, D. N. (1938), 'A generalization of Fisher's z test', Biometrika, vol 46: pp 59-66.

Lee, Y. (1971), 'Distribution of the canonical correlations and asymptotic expansions for distributions of certain independence test statistics', The Annals of Mathematical Statistics, vol 2: pp 526-537.

Levin, A., Lin, C. F. and Chu, C. (2002), 'Unit root tests in panel data: Asymptotic and finite sample properties', Journal of Econometrics, vol 108: pp 1-25.

Maddala, G. S. (1977), Econometrics, McGraw-Hill. 
Maddala, G. S. and Wu, S. (1999), 'A comparative study of unit root tests with panel data and a new simple test', Oxford Bulletin of Economics and Statistics, vol 61: pp 631-652.

Moon, H. R. and Perron, B. (2004), 'Testing for unit root in panels with dynamic factors', Journal of Econometrics, vol 122: pp 81-126.

Muirhead, R. J. (2005), Aspects of Multivariate Statistical Theory. Wiley.

Ng, S. and Perron, P. (1995), 'Unit root tests in ARMA models with data-dependent methods for the selection of the truncation lag', Journal of the American Statistical Association, vol 90: pp 268-281.

Perlman, M. D. and Olkin, I. (1980), 'Unbiasedness of invariant tests for MANOVA and other multivariate problems', The Annals of Statistics, vol 8(6): pp 1326-1341.

Pesaran, M. H. (2003), A simple panel unit root test in the presence of cross section dependence, Working paper, Trinity College, Cambridge.

Pesaran, M. H. (2007), 'A simple panel unit root test in the presence of cross-section dependence', Journal of Applied Econometrics, vol 22: pp 265-312.

Phillips, P. C. B. and Sul, D. (2003), 'Dynamic panel estimation and homogeneity testing under cross section dependence', Econometrics Journal, vol 6: pp 217-259.

Pillai, K. C. S. (1955), 'Some new test criteria in multivariate analysis', Annals of Mathematical Statistics, vol 26: pp 117-121.

Pillai, K. C. S. (1956), 'Some results useful in multivariate analysis', Annals of Mathematical Statistics, vol 27: pp 1106-1114.

Rao, C. R. (1973), Linear Statistical Inference and Its Applications Wiley.

Said, S. and Dickey, D. (1984), 'Testing for unit roots in autoregressive-moving average models of unknown order', Biometrika, vol 71: pp 599-607. 